\title{
Entrevista com Paulo Lins
}

Joelma Santana Siqueira (Universidade Federal de Viçosa) Vivaldo Andrade dos Santos (Georgetown University)

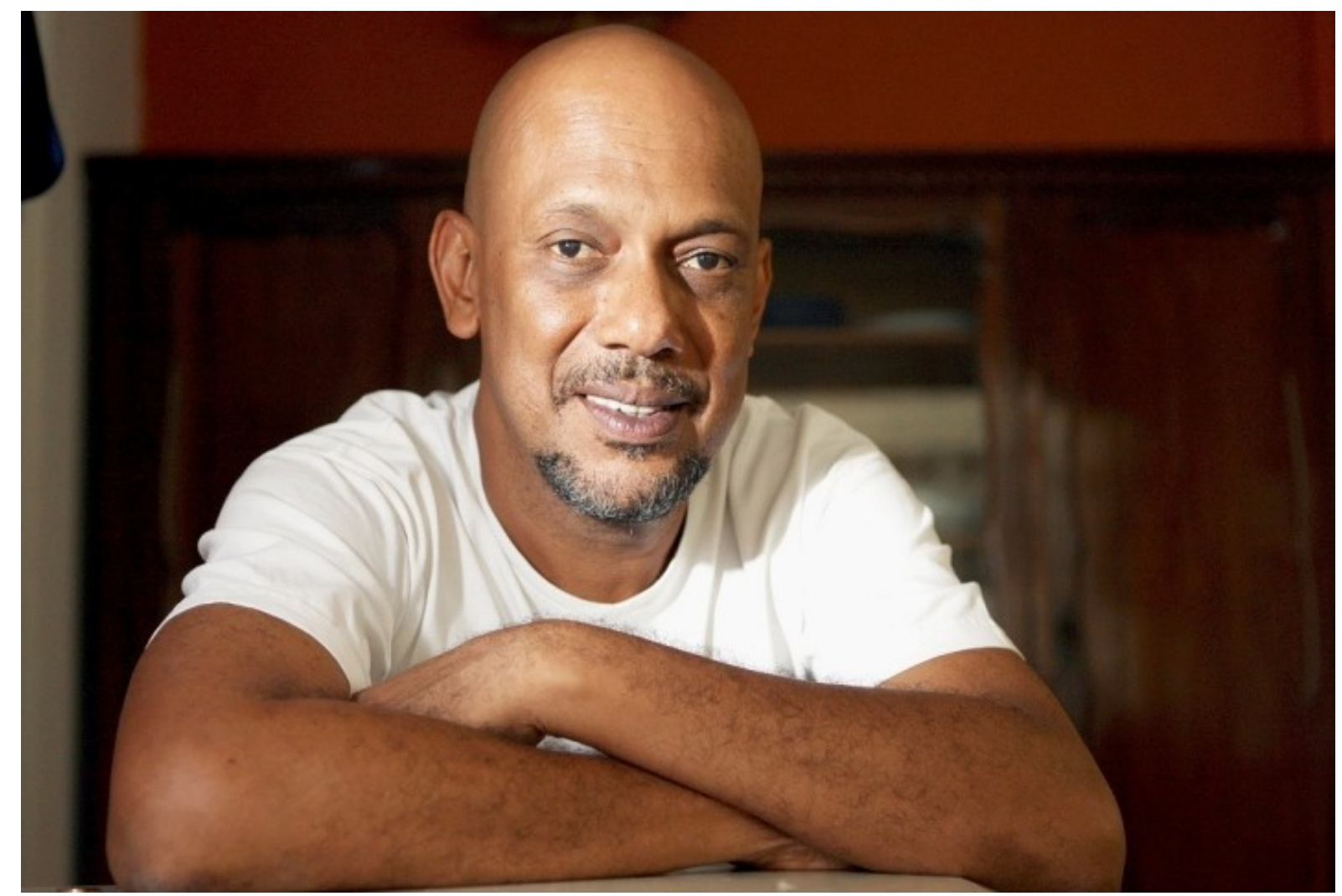

Fonte: Literafro (UFMG). Disponível em: http://www.letras.ufmg.br/literafro/autores/381-paulo-lins.

Paulo César de Souza Lins nasceu no Rio de Janeiro em 11 de junho de 1958. Entre os 6 anos e o início da idade adulta, residiu no conjunto Cidade de Deus. Graduado em Letras pela Universidade Federal do Rio de Janeiro (UFRJ), atuou como professor da rede pública de ensino do Estado. Na década de 1980, participou do grupo Cooperativa de Poetas e, em 1986, publicou o volume Sob o sol. Entre 1986 e 1993, integrou o grupo de pesquisadores liderado pela antropóloga Alba Zaluar em trabalho de campo sobre o perfil da violência na Cidade de

Gláuks: Revista de Letras e Artes-jul/dez. 2020 - v. 20, n. 2 
Deus, pesquisa que veio a contribuir para a criação do romance Cidade de Deus, concluído após o autor ter sido selecionado para a bolsa Vitae de Artes. Em 2002, o romance foi adaptado para o cinema por Fernando Meireles e Kátia Lund, recebendo indicações para o Globo de Ouro e o Oscar. Além dos romances Desde que o samba é samba (2012) e Era uma vez (2014), Lins redigiu episódios da série Cidade dos homens e o roteiro do filme Quase dois irmãos, de Lúcia Murat, pelo qual recebeu o prêmio de melhor roteiro da Associação Paulista de Críticos de Arte (APCA).

\section{Prezado Paulo Lins, somos muito gratos a você por nos conceder essa entrevista para o presente dossiê da Gláuks dedicado ao tema "A literatura brasileira no exterior". Para iniciarmos, pedimos que nos fale sobre como é escrever e publicar literatura no Brasil.}

Olha, escrever o primeiro livro é muito difícil, né? Você conseguir um editor, você fazer literatura. Eu comecei fazendo poesia e eu mesmo publicava os meus poemas, isso lá nos anos 80, era a literatura independente. Agora, o meu caso é muito especial porque eu fiz Cidade de Deus baseado numa pesquisa antropológica que era abrigada na Unicamp, no Instituto de Antropologia da Unicamp. Ela teve todo um aparato acadêmico de professores, de uma professora, Alba Zaluar, que faleceu no ano passado. Ela me ajudou muito. Era baseado numa pesquisa que eu fazia para ela. E depois eu tive o apoio do Roberto Schwarz, que leu 200 páginas do livro e praticamente arrumou a publicação na Companhia. Ela me deu o incentivo para eu ganhar a bolsa do CNPq, da FAPERJ, para escrever; e ele conseguiu a editora. Ele que me encaminhou para a Companhia das Letras. Agora, uma pessoa que não está participando de uma pesquisa de um trabalho universitário e quer fazer um livro, naquela época, publicar era muito difícil. Só quem publicava eram os poetas independentes que vinham de uma tradição da geração marginal. Porque só quem publicava poemas era Drummond. Poeta era só Drummond e alguns... Paulo Leminski publicava. São os poetas mais conhecidos assim. Mas o pessoal da poesia marginal, Chacal e aquele povo lá, publicava poesia independente. Então, veio a poesia marginal, veio a geração mimeógrafo que publicava seus próprios poemas... Agora, hoje em dia, tem muita editora alternativa. O próprio autor 
paga a sua edição. Paga a edição e depois desconta na vendagem. Ou tem editoras que fazem tiragens de 200, 300 e vai publicando. Já no exterior, aí é sorte, né? Você tem que ser publicado aqui, tem que sair na imprensa, tem que ter um editor de fora querendo te publicar.

\section{Você considera que há diferenças que mereçam ser destacadas entre a recepção que sua obra tem no Brasil e a que tem no exterior?}

Não, acho que eu tive o privilégio de ser muito bem aceito, tanto aqui no Brasil como no exterior. Antes mesmo de o livro ser publicado, eu já tinha o apoio de um crítico literário importante, o Roberto Schwarz. Então, ter o apoio de um intelectual do prestígio que ele tem, de seu reconhecimento acadêmico, para mim foi muito importante. No exterior, também. Eu tive muito privilégio. Eu fui privilegiado na questão do romance. Primeiro e segundo livros. Desde que o samba é samba recebeu críticas muito boas, tanto no Brasil, como no exterior, e depois virou filme. Muitas das traduções no exterior vêm depois do filme, então, ser adaptado para cinema é muito interessante para divulgar a obra.

\section{Qual a importância da tradução, sobretudo, para o escritor que escreve em português?}

Muitas pessoas não conheciam o Brasil. Para você ter uma ideia, achavam que Buenos Aires era a capital do Brasil. O Brasil é muito pouco divulgado no exterior. Só depois de Lula, quando Lula foi eleito, o Brasil apareceu mais no exterior. Lula com Obama, Obama dizendo que Lula era o cara. O Brasil e Gilberto Gil como Ministro da Cultura, tocando na ONU. O Brasil pagando a dívida externa, saindo do mapa da fome. O Brasil era um dos países que estava no mapa da fome, ele saiu e pagou a dívida externa, ficou conhecido. As pessoas começaram a visualizar mais a imagem do Brasil. E com Cidade de Deus também, depois do filme. Então, hoje, o Brasil é conhecido como não era antes. Acho que Lula trouxe essa imagem do Brasil para o exterior. E o futebol também alavancou o Brasil, a figura do Pelé.

Gláuks: Revista de Letras e Artes-jul/dez. 2020 - v. 20, n. 2 
Mas a literatura não era conhecida. Machado de Assis era pouco traduzido. Só quem era traduzido mesmo no exterior era Paulo Coelho e Jorge Amado. O Machado de Assis só era traduzido por algumas universidades que sabiam o valor dele, não era uma coisa que atingia o grande público. Agora, o Brasil está um pouco mais conhecido, mais atrativo. Mas, agora, Bolsonaro deu uma desequilibrada no Brasil...

\section{Quais são os desafios para ser publicado no exterior ou ser traduzido para outra língua?}

Desafio, não tem. Você tem que ter muita sorte, um editor se interessar por você. Por exemplo, nos Estados Unidos, o americano pouco lê a literatura estrangeira. Os europeus também. O francês, o alemão, o italiano...Vamos falar assim, nas quatro grandes línguas do mundo, o inglês, o francês, o espanhol e o alemão. Se, por exemplo, você for publicado em espanhol, dependendo de como você é publicado, você atinge metade do mundo. Você atinge a América do Sul, atinge a Espanha, atinge uma boa parte dos Estados Unidos. Ser publicado em inglês é muito difícil. Eles não consomem literatura brasileira. Os Estados Unidos pouco consomem literatura do exterior, eles se bastam. Não leem, não se interessam. Eles se acham no centro do mundo, todos têm que os ler, mas eles não leem o resto. É muito difícil. Jorge Amado, realmente, que é muito conhecido, e Paulo Coelho. Paulo Coelho abriu espaço. Ele faz esse tipo de literatura que a gente pode chamar de autoajuda, mas ele abriu muito espaço no exterior. Eu, por exemplo, fui publicado na Suécia, na Suíça, e o Paulo Coelho me ajudou a ir para um festival de literatura, uma feira literária, na Suécia. Ele faz assim: é convidado para essas feiras gigantes na Europa e fala "Eu só vou se chamar outro brasileiro". Ele não escolhe o brasileiro. E eu fui muito ao exterior assim. Deu uma força grande para isso.

\section{5. "Traduttore, traditore". Como é ler sua obra traduzida para outro idioma? Destacaria algum exemplo?}

Gláuks: Revista de Letras e Artes - jul/dez. 2020 - v. 20, n. 2 
Quando é em inglês e em espanhol, você pode até ajudar. Francês. Essas línguas que a gente costuma estudar no Brasil. A gente estuda espanhol, estuda inglês... Você pode até ajudar um pouco. Mas quando é traduzido para o alemão, como é que você vai ajudar, né? Eu fui traduzido para um país chamado Estônia, como é que vou ajudar? O francês eu ajudava. Eu tinha um tradutor francês que morava do lado da minha casa, no bairro Laranjeiras, no Rio de Janeiro. Como ele morava do lado da minha casa, eu ia lá para ajudar. Fui umas duas vezes.

\section{Existe uma "literatura nacional”, presa a um país, a uma região, a uma língua?}

O regionalismo foi uma coisa que teve muita discussão. Diminuía o escritor. O pessoal dizia que Guimarães Rosa era regionalista, imagina? Um sujeito com uma obra universal. Eu não acredito em regionalismo. Literatura é literatura. Toda literatura vai ter as características da sua região, do seu povo, da sua língua. Então, ela abarcar um tema não é regionalismo. Por exemplo, a literatura da periferia agora. Ela está abordando um tema, mas já está mudando. Por exemplo, Pixinguinha também é da periferia e olha o que ele fez. Cartola é da periferia. Não é uma literatura escrita, mas é poesia. Então, eu não acredito em regionalismo. Essa discussão é antiga, vem do modernismo isso do regionalismo.

\section{Seu fazer literário busca responder a alguma urgência presente na realidade social brasileira que você gostaria de destacar?}

Eu quero falar com minhas referências, lidar com aquilo que eu li. Eu quero dialogar com Mário de Andrade, dialogar com Maiakovski, dialogar com vários escritores. Tudo o que você escrever, se você quiser fazer uma referência com o mundo, com a realidade, você vai fazer. Agora, se é literatura, você tem que dialogar com aquilo que você leu, com aquilo que você gosta. Com as suas referências. Eu posso fazer um livro escrito como escrevi Cidade de Deus, como escrevi Desde que o samba é samba, e não ter um pingo de poesia. Eu posso 


\section{GLÁUKS}

relatar os fatos do momento. Agora, se tiver literatura, eu vou estar em sintonia com esse universo literário, esse universo poético. Porque senão, não vai ser literatura. Então, eu estando em sintonia, vou dialogar com o passado, com o presente e com a eternidade. Vou dialogar com aqueles que me influenciaram, com a literatura que eu gosto. Se você faz literatura, você é inespacial e atemporal. É isso o que a literatura é.

Entrevista transcrita por Laís de Oliveira Moreira. 